\title{
Editorial
}

\section{Dietary fibre and diabetes revisited}

\author{
$\mathrm{J}^{\mathrm{Mann}}{ }^{1}$ \\ ${ }^{1}$ Deparment of Human Nutrition, University of Otago, New Zealand
}

Dietary guidelines for people with diabetes appear to change from time to time and advice from various apparently authoritative sources differs - to the extent that those who have not carefully followed the reasoning behind the recommendations might be forgiven for being somewhat dismissive regarding the extent to which dietary treatment can influence glycaemic control and risk factor management. The recently revised 'Recommendations for the nutritional management of patients with diabetes mellitus' prepared by the Diabetes and Nutrition Study Group (DNSG) of the European Association for the Study of Diabetes (EASD) help to place in perspective apparent discrepancies between advice emanating from groups of researchers or expert committees (Diabetes and Nutrition Study Group, 2000). They explain that several different dietary patterns can often produce similar impressive improvements in glycaemic control and levels of cardiovascular risk factors. For example, diets low in saturated fats and moderately high in cis-unsaturated fatty acids are associated with comparable results to those achieved on a diet in which vegetables, fruits, wholegrain cereals and other appropriate carbohydrate-containing foods provide replacement energy for saturated fatty acids. However one issue which continues to cause some confusion relates to the most appropriate method for determining optimal carbohydrate-containing foods. What is the role of dietary fibre? Should the glycaemic index be the main determinant of carbohydrate-containing foods recommended as being particularly suitable for people with diabetes?

The potential role for dietary fibre in diabetes was first promoted more than $30 \mathrm{y}$ ago by Trowell on the basis of his experience in East Africa where he noted a virtual absence of what is now known as type 2 diabetes in association with the consumption of traditional diets which were extremely high in 'lightly processed' cereal foods (Mann, 1985). Uncontrolled clinical studies from Anderson's group in Kentucky followed. They demonstrated, in a relatively small number of insulin-treated patients (probably with type 2 diabetes), that introduction of a high carbohy-

*Correspondence: J Mann, Department of Human Nutrition, University of Otago, PO Box 56, Duredin, New Zealand.

E-mail: human-nutrition@otago.ac.nz

Received 12 April 2001; accepted 13 April 2001 drate-high fibre diet was associated with a dramatic improvement in glycaemic control and reduction in insulin dose (Kiehm et al, 1976). In fact such observations were not entirely new, similar observations having been made many years earlier by Kempner using his rice diet (Kempner et al, 1958). Inspired by the work of Anderson and also by the studies of Stone and Connor (1963), who drew attention to the potential of the low carbohydrate-high fat diet, then in widespread use, to increase cardiovascular risk, our own group in Oxford, England embarked on a series of carefully controlled studies which helped to further understand the role of dietary fibre (Simpson et al, 1979a; Simpson et al, 1979b; Simpson et al, 1981; Simpson et al, 1982; Lousley et al, 1984; Geekie et al, 1986; Mann, 1984). Each of the studies involved a crossover design in which patients with type 1 and type 2 diabetes were randomised to receive advice regarding the standard diabetic diet of the time, relatively low in carbohydrate and dietary fibre, or an experimental high carbohydrate diet. After 6 weeks on the first diet participants crossed over to the alternative diet for a similar length of time. The patients were all free-living and meals were prepared at home under the close supervision of research dietitians. A range of measures of glycaemic control and lipoprotein-related cardiovascular risk factors were the principal outcome measures.

Our studies clearly showed improved glycaemic control and reduced total and LDL cholesterol on a diet relatively low in fat and in which readily obtainable fibre-rich foods accounted for the increased intake of carbohydrate (Simpson et al, 1979a; Simpson et al, 1979b; Simpson et al, 1981; Lousley et al, 1984). The improvement was particularly striking when foods rich in soluble fibre were encouraged (Simpson et al, 1981). The early studies were criticised on the grounds that we could not distinguish between the beneficial effects of carbohydrates per se and dietary fibre, but later studies in which carbohydrate alone was increased left little doubt that in order to achieve improved glycaemic control and reduced LDL without any increase in VLDL and triglycerides or reduction in HDL it was essential to increase dietary fibre, especially soluble fibre (Simpson et al, 1982). We were also able to show that it was possible to achieve beneficial effects with more acceptable amounts of dietary fibre than had been used in our earlier studies (Lousley et al, 1984). Other groups publishing at around the same time or 
shortly afterwards produced broadly comparable results (Rivellese et al, 1980; Riccardi et al, 1984). Those who were unable to duplicate these findings may have used foods which were not sufficiently rich in soluble fibre (Hollenbeck et al, 1988).

At the same time as our studies using whole foods were being started, Jenkins and his colleagues, also working in Oxford, were undertaking studies with guar gum and other soluble forms of dietary fibre (Jenkins et al, 1976; Jenkins et al, 1977). They demonstrated that the addition of these preparations as supplements to carbohydrate-containing meals reduced the glycaemic excursion following such meals. This work initiated by Jenkins and Wolever has been duplicated by researchers throughout the world using a range of purified or semi-purified gums, mucilages and other forms of soluble fibre (Smith et al, 1982; Smith \& Holm 1982). In addition to the acute effects, some studies showed an overall improvement in glycaemic control when these fibres were incorporated into foods or used as supplements (Aro et al, 1981), but the improvements were usually less marked than those achieved with the use of fibre-rich whole foods. Furthermore it seems that for technological reasons it was difficult to incorporate such fibres into palatable food products and their use in diabetes management has thus far been limited in most countries.

Jenkins, Wolever and colleagues were also responsible for the introduction of the concept of glycaemic index (GI) of carbohydrate-containing foods, ie the glycaemic excursion (measured as area under the blood glucose response curve in $\mathrm{mmol} / \mathrm{min} / \mathrm{l}$ ) following ingestion of a standard amount of food (usually 50 or $100 \mathrm{~g}$ ) expressed as a percentage of the glycaemic excursion following an equivalent amount of a carbohydrate standard (50 or $100 \mathrm{~g}$ of glucose or white bread) (Jenkins et al, 1981; Wolever \& Jenkins, 1986). Slowly absorbed carbohydrate-containing foods (eg various cooked dried beans such as lentils and chick peas, brown spaghetti and parboiled rice) have lower GIs than those containing rapidly absorbed carbohydrates (eg breakfast cereals such as cornflakes, ripe bananas and mashed potato) (Foster-Powell \& Brand Miller, 1995). Although the term glycaemic index came to be widely used in the early 1980s, the idea that similar amounts of carbohydrate in different foods resulted in varying glycaemic responses had been suggested several years earlier by researchers in several different countries (Truswell, 1992). The GI of foods depends upon several different attributes, including the nature of the carbohydrate component, the cooking or food processing, and other food components eaten at the same time (FAO/WHO, 1998; Brand et al, 1985).

A diet in which low GI foods provide a high proportion of all dietary carbohydrate improves long-term glycaemic control and plasma lipids (Wolever et al, 1992). Innumerable publications from many research groups in different countries have now reported GI values for locally available foods and in some countries the GI concept has become the means of identifying the most appropriate carbohydratecontaining foods for people with diabetes. While some low GI foods are high in soluble forms of dietary fibre (eg lentils, chickpeas, other dried beans), this is not invariably the case.

After a hiatus of several years during which little new information emerged, several recent publications have helped to clarify the extent to which knowledge of glycaemic index and dietary fibre content of carbohydratecontaining foods are useful when prescribing diets for people with diabetes. Jarvi and colleagues undertook a landmark controlled study in which individuals with type 2 diabetes were provided with fairly similar meals which, through use of skilled food technology, differed only in glycaemic index (Jarvi et al, 1999). Macronutrient composition and dietary fibre content were identical on the two diets. After 24 days, the low glycaemic index diet was associated with improved glycaemic control, reduced total and LDL cholesterol and reduced levels of plasminogen activator inhibitor-I (PAI-I) when compared with the high glycaemic index diet, thus confirming the ability of low GI foods to confer benefit, independent of dietary fibre, in terms not only of blood glucose control and lipoprotein mediated cardiovascular risk reduction, but also a reduction in thrombogenic risk (reduced PAI-I).

Chandalia et al have reexamined the role of dietary fibre in type 2 diabetes comparing average ( $24 \mathrm{~g} /$ day total, $8 \mathrm{~g}$ soluble) and high ( $50 \mathrm{~g} /$ day total, $25 \mathrm{~g}$ soluble) fibre diets using an experimental design similar to that which we used in our early studies, ie a 6 week randomised crossover design (Chandalia et al, 2000). However there were several important differences. The experimental diets were identical in macronutrient composition, reduced in total and low in saturated fatty acids (30 and 7\% total energy) and average in total carbohydrate and protein content (55 and 15\% total energy). Furthermore dietary intake was more carefully controlled by providing the participants with all their meals. Reductions in plasma glucose and insulin and urinary glucose excretion throughout a $24 \mathrm{~h}$ period on the high, compared with the average fibre diet, were virtually identical to those we observed nearly $20 \mathrm{y}$ ago, as were the improvements in lipids and lipoproteins. The increase in soluble fibre was achieved by increasing a range of unfortified foods, vegetables, fruit and wholegrain cereals (eg cantaloupe, grapefruit, orange, papaya, raisins, lima beans, okra, sweet potato, winter squash, zucchini, granola, oatbran) and no fibre supplements. Glycaemic index data are not presented for these foods or the meals as a whole but from published data it would seem that, while some do indeed have a low GI (eg lima beans), most others would be defined as having an intermediate index (eg sweet potato, oatbran, granola, orange and papaya). Additional recent support for the usefulness of dietary fibre in type 1 diabetes comes from the EURODIAB study, which suggested better glycaemic control and reduced episodes of ketoacidosis in those with highest intakes (Buyken et al, 1998)

Thus it would seem to be inappropriate to dismiss the usefulness of soluble dietary fibre in the management of patients with types 1 and 2 diabetes in favour of the exclusive use of GI. High soluble fibre-containing foods and low GI foods improve diabetes control at least in part 
as a result of delayed glucose absorption. In type 2 diabetes, given the diminished first-phase insulin response, there is a better match between the maximum blood glucose concentration after a carbohydrate-containing meal and the delayed insulin response. Other mechanisms by which low GI and high fibre foods achieve reduced postprandial hypoglycaemia are more speculative but it is important to emphasise that the benefits of increased fibre intake result principally from the greater consumption of soluble forms. While insoluble forms of dietary fibre may confer benefit in terms of maintaining gastrointestinal health, such fibres appear to have a smaller effect on carbohydrate and lipid metabolism. Unfortunately the methodology presently available for measuring these subtypes of dietary fibre are imperfect and the WHO/FAO Expert Consultation on Carbohydrates has suggested the measurement of non-starch polysaccharides rather than dietary fibre, with specification regarding the type of polysaccharide, eg gums, pectins, mucilages. This is impractical for clinical use. Until methodology has been further improved it may be best to advise patients with diabetes to select carbohydrate-containing foods from lists of those rich in appropriate dietary fibres and which are regionally available, rather than to suggest amounts of soluble fibre which must be consumed. Indeed the same advice may be applied to choices based on glycaemic index. Although glycaemic index is, in theory, easy to determine, there is considerable individual variation in this biological index, even when measured under standardised conditions. Low GI foods (those with a GI below 55) and intermediate GI foods (GI 55-70) which are also rich in soluble fibre represent the most appropriate choices of carbohydrate-containing foods.

Perhaps the most important message to emerge from this discussion is the reminder of the extent to which dietary management can contribute to diabetes management in types 1 and 2 diabetes. A new drug which could reproduce the range of benefits associated with soluble fibre rich or low GI foods would be heralded as a major breakthrough and rapidly become a best seller. Dietary modification would seem to be a far better option.

\section{References}

Aro A, Uusitupa M, Voutilainen E, Hersio K, Korhonen T \& Siitonen O (1981): Improved diabetic control and hypocholesterolaemic effect induced by long-term dietary supplementation with guar gum in type 2 (insulin-independent) diabetes. Diabetologia 21, 29-33.

Brand JC, Nicholson PL, Thorburn AW \& Truswell AS (1985): Food processing and the glycaemic index. Am. J. Clin. Nutr. 42, 1192-1196.

Buyken AE, Toeller M, Heitkamp G, Vitelli F, Stehle P, Scherbaum WA \& Fuller JH (1998): Relation of fibre intake to HbAlc and the prevalence of severe ketoacidosis and severe hypoglycaemia. EURODIAB IDDM Complications Study Group. Diabetologia 41, 882-890.

Chandalia M, Garg A, Lutjohann D, von Bergmann K, Grundy SM \& Brinkley LJ (2000): Beneficial effects of high dietary fiber intake in patients with type 2 diabetes mellitus. New Engl. J. Med. 342, 1392-1398.

Diabetes and Nutrition Study Group (DNSG) of the European Association for the Study of Diabetes (EASD), 1999 (2000): Nutritional recommendations for the nutritional management of patients with diabetes mellitus. Eur. J. Clin. Nutr. 54, 353-355.
Food and Agriculture Organization/World Health Organization (1998): Carbohydrates in human nutrition. Report of a Joint FAO/WHO Expert Consultation FAO Food and Nutrition, paper 66, 140pp. Geneva: WHO.

Foster-Powell K \& Brand Miller J (1995): International tables of glycemic index. Am. J. Clin. Nutr. 62, 871S-893S.

Geekie MA, Porteous J, Hockaday TDR \& Mann JI (1986): Acceptability of high-fibre diets in diabetic patients. Diabetic Med. 3, 65-68.

Hollenbeck CB, Coulston AM, Reaven GM, Slama, G \& Mann JI (1988) The diabetic dietary prescription: an ongoing controversy. Diabetes Nutr. Metab. 1, 239-254.

Jarvi AE, Karlström BE, Grandfeldt YE et al (1999): Improved glycemic control and lipid profile and normalized fibrinolytic activity in a lowglycemic index diet in type 2 diabetic patients. Diabetes Care 22, 10-18.

Jenkins DJA, Goff DV, Leeds AR, Alberti KGMM, Wolever TMS, Gassull MA \& Hockaday TDR (1976): Unabsorbable carbohydrates and diabetes: decreased post-prandial hyperglycaemia. Lancet ii, 172-174.

Jenkins DJA, Leeds AR, Gassull MA, Cochet B \& Alberti KGMM (1977): Decrease in post-prandial insulin and glucose concentrations by guar and pectin. Ann. Intern. Med. 86, 20-23.

Jenkins DJA, Wolever TMS, Taylor RH et al (1981): Glycemic index of foods: a physiological basis for carbohydrate exchange. Am. J. Clin. Nutr. 34, 362-366.

Kempner W, Pescheli RL \& Schlayer C (1958): Effect of rice diet on diabetes mellitus associated with vascular disease. Postgrad. Med. 24, 359.

Kiehm TG, Anderson JW \& Ward K (1976): Beneficial effects of a high carbohydrate, high fiber diet on hyperglycemic diabetic men. Am. J. Clin. Nutr. 29, 895-899.

Lousley SE, Jones DB, Slaughter P, Carter RD, Jelfs R \& Mann JI (1984): High-carbohydrate-high fibre diets in poorly controlled diabetes. Diabetic Med. 1, 21-25.

Mann JI (1984): Lines to legumes: Changing concepts of diabetic diets. Diabetic Med. 1, 191-198

Mann JI (1985): Diabetes Mellitus: some aspects of aetiology and management. In Refined Carbohydrate Foods, Dietary Fibre and Disease, 2nd edn, eds. HC Trowell, D Burkitt, K Heaton, pp 263-287. London: Academic Press.

Riccardi G, Rivellese A, Pacioni D, Genovese S, Mastranzo P \& Mancini M (1984): Separate influence of dietary carbohydrate and fibre on the metabolic control in diabetes. Diabetologia 26, 116-121.

Rivellese A, Riccardi G, Giacco A et al (1980): Effect of dietary fibre on glucose control and serum lipoproteins in diabetic patients. Lancet ii, $447-450$.

Simpson RW, Mann JI, Eaton J, Moore RA, Carter R \& Hockaday TDR (1979a): Improved glucose control in maturity-onset diabetes treated with high-carbohydrate-modified fat diet. Br. Med. J. 1, 1753-1756.

Simpson RW, Mann JI, Eaton J, Carter RD \& Hockaday TDR (1979b): High-carbohydrate diets and insulin dependent diabetics. Br. Med. J. 2, $523-525$.

Simpson HCR, Simpson RW, Lousley S, Carter RD, Geekie M, Hockaday TDR \& Mann JI (1981): A high carbohydrate leguminous fibre diet improves all aspects of diabetic control. Lancet $\mathbf{i}, 1-5$.

Simpson HCR, Carter RD, Lousley S \& Mann JI (1982): Digestible carbohydrate - an independent effect on diabetic control in type II (non-insulin dependent) diabetic patients? Diabetologia 23, 235-239.

Smith CJ, Rosman MS, Levitt NS \& Jackson WP (1982): Guar biscuits in the diabetic diet. S. Afr. Med. J. 61, 196-198.

Smith U \& Holm G (1982): Effect of a modified guar gum preparation on glucose and lipid levels in diabetics and healthy volunteers. Atherosclerosis 45, $1-10$.

Stone DB \& Connor WE (1963): The prolonged effects of a low cholesterol, high carbohydrate diet upon the serum lipids in diabetic patients. Diabetes 12, 127-132.

Truswell AS (1992): Glycaemic index of foods. Eur. J. Clin. Nutr. 46(Suppl), S91-S101.

Wolever TMS \& Jenkins DJA (1986): The use of the glycemic index in predicting the blood glucose response to mixed meals. Am. J. Clin. Nutr. 43, $167-172$

Wolever TMS, Jenkins DJA, Vuksan V et al (1992): Beneficial effect of a low-glycemic index diet in type 2 diabetes. Diabetic Med. 9, 451-458. 